\title{
Prehospital identification of major trauma patients
}

\author{
Gürbey Ocak • Leontien M. Sturms • \\ Josephine M. Hoogeveen • Saskia Le Cessie • \\ Gerrolt N. Jukema
}

Received: 8 November 2007 / Accepted: 18 April 2008 / Published online: 26 June 2008

(C) The Author(s) 2008

\begin{abstract}
Background and aims Prehospital triage is aimed at getting the right patient to the right hospital. Evaluations on the performance of prehospital triage tools are scarce. This study examines the ability of the American College of Surgeons' Committee on Trauma (ACSCOT) triage guidelines to identify major trauma patients in a European trauma system. Furthermore, this study evaluates the predictive power of other prehospital measurements.

Materials and methods Prehospital data of 151 minor (Injury Severity Score (ISS) 1-15) and 151 major trauma patients, (ISS $>15$ ) treated at a Dutch trauma center, were collected. Logistic regression analysis was used to identify predictors of major trauma patients.

Results The major trauma patients particularly incurred severe head injuries (45.7\%) and severe thorax injuries $(21.9 \%)$. The ACSCOT guidelines had a sensitivity of $84.1 \%$ and a specificity of $77.5 \%$. A new prehospital trauma triage model was constructed including nine
\end{abstract}

\section{G. Ocak}

Department of Surgery, Leiden University Medical Center,

Leiden, The Netherlands

\section{M. Sturms}

Trauma Center West-Netherlands,

Leiden University Medical Center,

Leiden, The Netherlands

J. M. Hoogeveen • G. N. Jukema $(\bowtie)$

Department of Trauma Surgery, VU University Medical Center,

P.O. Box 7057, 1007 MB, Amsterdam, The Netherlands

e-mail: g.jukema@vumc.nl

\section{S. Le Cessie}

Department of Medical Statistics,

Leiden University Medical Center,

Leiden, The Netherlands predictors of major trauma. This model identified more major trauma patients than the ACSCOT (sensitivity $92.1 \%, p=0.023$ ) and resulted in a comparable specificity $(79.5 \% ; p=0.711)$.

Conclusion The new triage model outperforms the ACS COT triage guidelines in identifying major trauma patients in the prehospital setting. The new triage guidelines may improve patient outcomes but needs to be validated in a prospective study.

Keywords Multiple trauma · Triage - Trauma centers · Europe

\section{Introduction}

In Europe, injuries cause $9 \%$ of deaths and $14 \%$ of ill health [1]. Worldwide, injuries are even the leading cause of death in people under 45 years of age [2]. Moreover, injuries can result in long-term dysfunction among the survivors [2]. Improved outcomes can be achieved through reorganization of the trauma care. Studies, mainly from the US, have demonstrated beneficial effects of regionalization of trauma care, including designating trauma centers. Trauma center treatment has shown to decrease the risk of death and improve functional outcomes after specifically severe injury [3-5].

In Europe, there is a great variation in the organization of trauma care [6]. Many European countries have designated trauma centers [7]. In 2002, it was estimated that most of the European trauma centers receive between 100 and 200 major trauma patients per year [8]. In Germany, it was estimated that only about half of all the major trauma patients is treated in trauma centers [9]. Moreover, underutilization of the trauma centers was suspected for 
other European countries as well [9]. This may lead to adverse outcomes caused by delayed interventions and higher costs due to transfers.

The reason why not all major trauma patients are directly transported to a trauma center is unclear. Possibly, primary stabilization of the major trauma patient at a regional hospital is chosen in case of long distances to a trauma center. However, the severely injured patients may also be overlooked in the field. For the identification of these patients, various prehospital triage guidelines have been developed to assist paramedic judgment [10]. Yet, only few studies have evaluated the performance of triage tools in European datasets [11-13]. In general, these studies have reported on poor performances and there is no consensus on which tool is best in identifying major trauma patients in the field.

In the US, the American College of Surgeons published one of the first field triage protocols for trauma patients in 1987 [14]. During the past 20 years, these guidelines, including physiological, anatomic, and mechanism of injury criteria, have been further developed by the American College of Surgeons' Committee on Trauma (ACSCOT). Studies in the US have revealed that $95-97 \%$ of the major trauma patients can be identified by these guidelines [1517]. The ACSCOT guidelines have not yet been evaluated for a European dataset. In view of differences between the injury profiles of US and European trauma populations as well as geographical differences, such an evaluation is needed.

The purpose of this study was to evaluate the performance of the ACSCOT field triage criteria in a European, i.e., Dutch, trauma system. Furthermore, the injury profiles and prehospital characteristics of minor and major trauma patients were compared to identify prehospital predictors of major trauma patients to examine whether we could introduce a simpler prehospital triage model.

\section{Materials and methods}

This study was carried out at one of the ten Dutch trauma centers, i.e., the Trauma Center West-Netherlands (TCWN). The TCWN is comprised of three level-one hospitals: the Leiden University Medical Center, the Haaglanden Medical Center, and the Leyenburg Hospital. The TCWN serves a population of approximately 1.8 million people.

The regional trauma registry of the TCWN was used to identify the study population. For this study, we included all major adult trauma patients $(\geq 18$ years) who were transported by ambulance from the accident scene and were admitted to the TCWN between July 2004 and June 2005 (Fig. 1). Major trauma patients were defined according to an Injury Severity Score (ISS) of $>15$ [18]. The ISS is based on the Abbreviated Injury Scale (AIS) [19].
Fig. 1 Flow diagram of inclusion of the study population

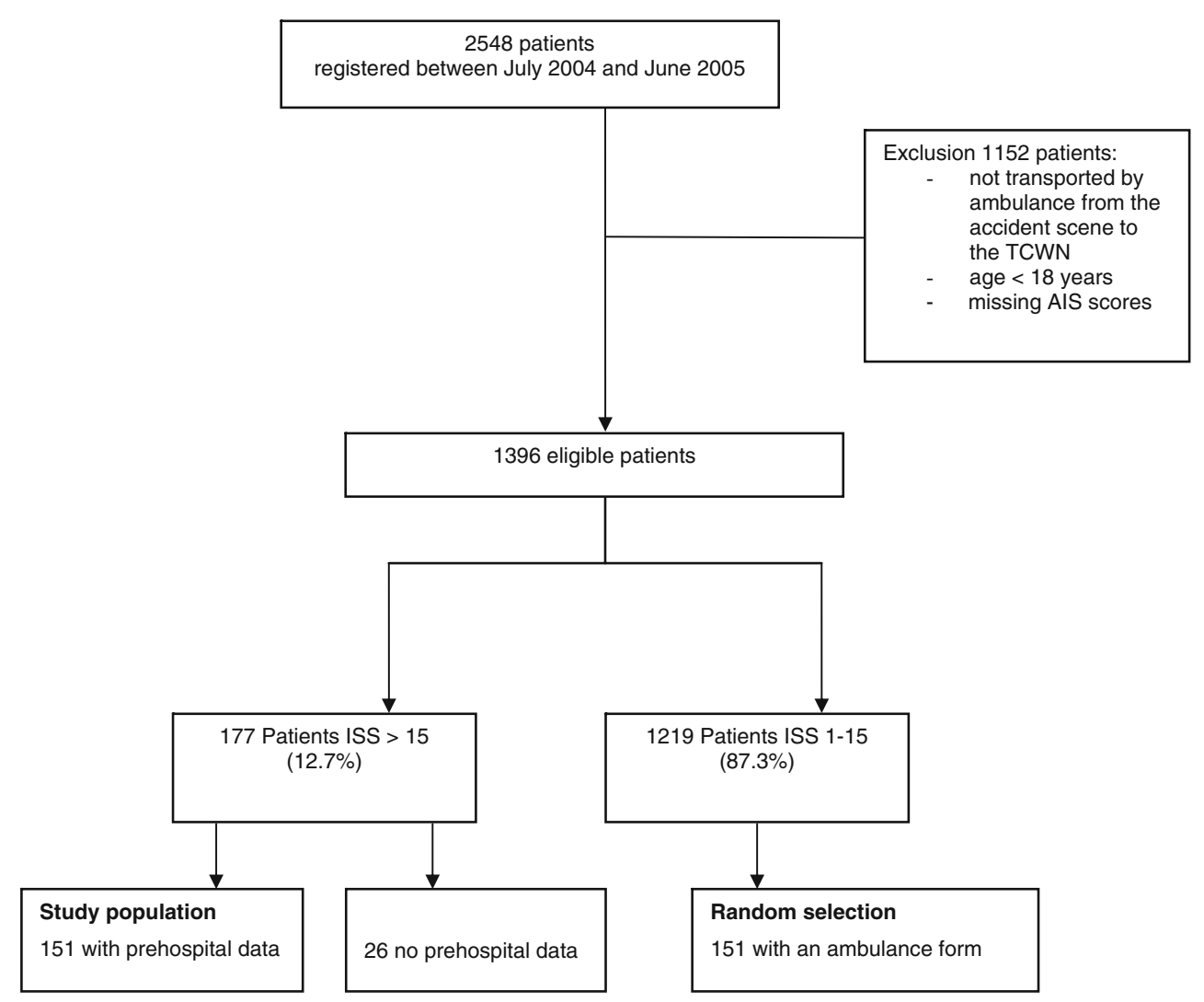


The ambulance forms of the major trauma patients were collected and all standardized items were registered. The ambulance form could not be traced for 26 major trauma patients. The mean ISS, the mean age, and the gender distribution of these 26 major trauma patients did not differ significantly from the 151 major trauma patients with ambulance forms $(p>0.05)$. Furthermore, we selected a random control group of 151 trauma patients with minor through moderate injuries (ISS 1-15). This control group included the same number of patients treated at the three TCWN hospitals as in the major trauma group. The mean ISS, the mean age, and the gender distribution of the random sample did not differ from the total group of minor trauma patients with an ISS of $1-15(p>0.05)$.

The ambulance forms are filled out by ambulance paramedics at the scene. The ambulance forms include all items of the ACSCOT guidelines except for five mechanism of injury descriptors (ejection from automobile, death in same passenger compartment, extrication time $>20 \mathrm{~min}$, rollover, and pedestrian thrown or run over) [14]. With respect to the physiological parameters, we used the first measurements the paramedic made at arrival at the scene, without any interventions having taken place yet.

Statistical comparisons between the characteristics of the major and minor trauma patients were conducted using $t$ tests, Mann-Whitney tests, chi-square tests, and Fisher's exact tests. Mean values are presented with their standard deviations $(\mathrm{SD})$ as mean $( \pm \mathrm{SD})$.

To determine prehospital predictors of major trauma patients, we entered the items of the ambulance forms, including ACSCOT items, in stepwise forward and backward logistic regression analyses using an inclusion and removal criterion of $p=0.05$. A revised prehospital triage model was constructed consisting of the items selected by the logistic regression completed with all the anatomic ACSCOT descriptors corresponding to AIS 4 codes. The sensitivity, specificity, accuracy, positive (PPV) and negative predictive values (NPV) were calculated for both the ACSCOT and the newly developed triage model. The McNemar's test was applied to compare the sensitivity and the specificity of the ACSCOT model with the new triage model. The original prevalence of the major and minor trauma patients was used to calculate the PPV and the NPV as well as the accuracy, the sensitivity, and specificity for ISS $\geq 18$ and ISS $\geq 30$ cutoff values. A $p$ value of $<0.05$ was considered significant.

\section{Results}

The main characteristics of the 151 major and 151 minor trauma patients are given in Table 1. The major trauma patients were significantly younger and concerned more
Table 1 Main characteristics

\begin{tabular}{lccr}
\hline & $\begin{array}{l}\text { ISS }>15 \\
(N=151)\end{array}$ & $\begin{array}{l}\text { ISS } 1-15 \\
(N=151)\end{array}$ & \multicolumn{1}{l}{$p$} \\
\hline Age, mean ( \pm SD) & $48.4( \pm 23.7)$ & $59.7( \pm 23.3)$ & $<0.001$ \\
Male, $N(\%)$ & $105(69.5)$ & $76(50.3)$ & 0.001 \\
ISS, mean $( \pm$ SD) & $23.7( \pm 8.7)$ & $7.5( \pm 2.9)$ & $<0.001$ \\
Mortality,$N(\%)$ & $26(17.2)$ & $2(1.3)$ & $<0.001$ \\
ICU stay, $N(\%)$ & $100(66.9)$ & $11(7.3)$ & $<0.001$ \\
Blunt injury, $N(\%)$ & $144(95.4)$ & $143(94.7)$ & 0.791 \\
Mechanism of injury & & & \\
Traffic, $N(\%)$ & $79(52.3)$ & $53(35.1)$ & $<0.001$ \\
Home-leisure, $N(\%)$ & $43(28.5)$ & $81(53.6)$ & \\
Sport, $N(\%)$ & $5(3.3)$ & $2(1.3)$ & \\
Violence, $N(\%)$ & $6(4.0)$ & $9(6.0)$ & \\
Self-inflicted, $N(\%)$ & $6(4.0)$ & $1(0.7)$ & \\
Work, $N(\%)$ & $11(7.3)$ & $4(2.6)$ & \\
Unknown, $N(\%)$ & $1(0.7)$ & $1(0.7)$ & \\
\hline
\end{tabular}

ISS Injury Severity Score, ICU Intensive Care unit

${ }^{\text {a }}$ Mortality defined as survival or death at hospital discharge

male patients. The mean ISS of the major trauma patients was $23.7( \pm 8.7)$ with $62.3 \%$ of the major trauma patients having an ISS of $16-24$ and $37.7 \%$ an ISS $\geq 25$. Of the minor trauma patients, $38.4 \%$ had an ISS less than nine and $61.6 \%$ had an ISS of $9-15$. Most major trauma patients were injured in traffic, whereas many minor trauma patients incurred home or leisure injuries. Furthermore, the major trauma patients were more often admitted to the Intensive Care Unit (ICU) and had a higher mortality rate.

Over three quarter of the major trauma patients incurred a head injury $(77.5 \%)$, compared to $28.5 \%$ of the minor trauma patients $(p<0.001)$. Furthermore, the major trauma patients sustained significantly more thorax $(47.7 \%)$, face (27.2\%), and abdomen (21.2\%) injuries compared to the minor trauma patients (respectively, 7.9\%, 6.6\%, and 5.3\%; $p<0.001)$. On the other hand, the minor trauma patients incurred more extremity injuries $(69.5 \%)$ than the major trauma patients $(41.7 \% ; p<0.001)$. Table 2 shows the distribution of the severity of the injuries within the ISS body regions. The most serious injuries (i.e., AIS 4-6) of the major trauma patients concerned head and thorax injuries.

The number of trauma patients who met the ACSCOT items is presented in Table 3. Overall, ACSCOT had a sensitivity of $84.1 \%$, a specificity of $77.5 \%$, a PPV of $35.2 \%$, a NPV of $97.1 \%$, and an accuracy of $78.3 \%$ for ISS $>15$. For ISS cutoff values of ISS $\geq 18$ and ISS $\geq 30$, the ACSCOT model showed a sensitivity of respectively $91.3 \%$ and $100 \%$ and a specificity of $75.8 \%$ and $70.9 \%$. More than half of the major trauma patients had a Glasgow Coma Scale $(\mathrm{GCS})<14(58.9 \%)$, but only $15.2 \%$ had a 
Table 2 Abbreviated injury scale scores within the Injury Severity Score body regions

\begin{tabular}{|c|c|c|c|c|}
\hline & \multicolumn{2}{|c|}{$\mathrm{ISS}>15(N=151)$} & \multicolumn{2}{|c|}{ ISS $1-15(N=151)$} \\
\hline & $N$ & $\%$ & $N$ & $\%$ \\
\hline \multicolumn{5}{|c|}{ Maximal AIS score, overall } \\
\hline $1-2$ & 0 & 0.0 & 68 & 45.0 \\
\hline 3 & 36 & 23.8 & 83 & 55.0 \\
\hline $4-6$ & 115 & 76.2 & 0 & 0.0 \\
\hline \multicolumn{5}{|c|}{ Maximal AIS score, head } \\
\hline $0^{\mathrm{a}}$ & 34 & 22.5 & 108 & 71.5 \\
\hline $1-2$ & 25 & 16.6 & 36 & 23.8 \\
\hline 3 & 23 & 15.2 & 7 & 4.6 \\
\hline $4-6$ & 69 & 45.7 & 0 & 0.0 \\
\hline \multicolumn{5}{|c|}{ Maximal AIS score, thorax } \\
\hline $0^{\mathrm{a}}$ & 79 & 52.3 & 139 & 92.1 \\
\hline $1-2$ & 10 & 6.6 & 9 & 6.0 \\
\hline 3 & 29 & 19.2 & 3 & 2.0 \\
\hline $4-6$ & 33 & 21.9 & 0 & 0.0 \\
\hline \multicolumn{5}{|c|}{ Maximal AIS score, abdomen } \\
\hline $0^{\mathrm{a}}$ & 119 & 78.8 & 143 & 94.7 \\
\hline $1-2$ & 14 & 9.3 & 6 & 4.0 \\
\hline 3 & 6 & 4.0 & 2 & 1.3 \\
\hline $4-6$ & 12 & 7.9 & 0 & 0.0 \\
\hline \multicolumn{5}{|c|}{ Maximal AIS score, face } \\
\hline $0^{\mathrm{a}}$ & 110 & 72.8 & 141 & 93.4 \\
\hline $1-2$ & 36 & 23.8 & 10 & 6.6 \\
\hline 3 & 5 & 3.3 & 0 & 0.0 \\
\hline $4-6$ & 0 & 0.0 & 0 & 0.0 \\
\hline \multicolumn{5}{|c|}{ Maximal AIS score, extremities } \\
\hline $0^{\mathrm{a}}$ & 88 & 58.3 & 46 & 30.5 \\
\hline $1-2$ & 34 & 22.5 & 34 & 22.5 \\
\hline 3 & 26 & 17.2 & 71 & 47.0 \\
\hline $4-6$ & 3 & 2.0 & 0 & 0.0 \\
\hline \multicolumn{5}{|c|}{ Maximal AIS score, external } \\
\hline $0^{\mathrm{a}}$ & 57 & 37.7 & 105 & 69.5 \\
\hline $1-2$ & 81 & 53.6 & 46 & 30.5 \\
\hline 3 & 4 & 2.6 & 0 & 0.0 \\
\hline $4-6$ & 9 & 6.0 & 0 & 0.0 \\
\hline
\end{tabular}

ISS Injury Severity Score, AIS Abbreviated Injury Scale

${ }^{a}$ Maximal AIS score of 0 reflects no injury in the respective ISS body region.

deviant respiratory rate (RR) and no more than $9.3 \%$ had a systolic blood pressure (SBP) less than 90. Specifically, severe injuries to the thorax and abdomen are expected to cause unstable vital signs reflected by problems with respectively breathing and a lowered SBP. However, only $15.2 \%$ of the patients with AIS $\geq 4$ thorax injuries appeared to have a RR $>29$ or $\mathrm{RR}<10$ and $25.0 \%$ of the patients with AIS $\geq 4$ abdominal injuries had a $\mathrm{SBP}<90$.

In addition to the ACSCOT items, we also reviewed other items from the ambulance forms (Table 4). Major trauma patients had more pupil disorders defined as anisocoria or abnormal light reflex $(p<0.001)$, blood loss from ear, nose, or mouth $(p<0.001)$, vomiting $(p<0.001)$, loss of consciousness $(p<0.001)$, compression pain on the thorax $(p=0.002)$, abdominal compression pain and rebound tenderness $(p=0.014)$, paleness $(p<0.001)$, and clamminess $(p=0.015)$.

Both the forward and backward stepwise logistic regression analyses, entering all ACSCOT items (Table 3) and the additional items from the ambulance forms (Table 4), except the items which occurred more often in the minor trauma patients, resulted in five independent predictors of major trauma (Table 5). Based on these analyses, an alternative prehospital triage model was composed. This model includes the five items significant in logistic regression as well as four ACSCOT anatomic

Table 3 Evaluation of the American College of Surgeons' Committee on Trauma triage guidelines

\begin{tabular}{llll}
\hline $\begin{array}{l}\text { ISS }>15 \\
(\mathrm{~N}=151)\end{array}$ & & $\begin{array}{l}\text { ISS } 1-15 \\
(N=151)\end{array}$ \\
\cline { 5 - 6 }$\%$ & & $N \quad \%$ \\
\hline
\end{tabular}

Physiological component

GCS $<14$

$\mathrm{SBP}<90$

$\mathrm{RR}<10$ or $>29$

Patients with at least one of these

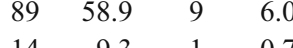

$$
\text { criteria }
$$

Anatomic component

Penetrating injuries to head, neck, and torso

Flail chest

Two or more proximal long

bone fractures

Instable pelvic fractures

Open and depressed skull fracture

Paralysis

Amputation proximal to wrist and ankle

Major burns

Patients with at least one of

$\begin{array}{llll}23 & 15.2 & 1 & 0.7\end{array}$

these criteria

Mechanism of injury component

Fall $>20 \mathrm{ft}$

High-speed auto crash

Auto-pedestrian injury

Auto-motor or cycle injury

Motorcycle crash $>20 \mathrm{mph}$

Patients with at least one

$\begin{array}{llll}95 & 62.9 & 10 & 6.6\end{array}$

of these criteria

\section{ACSCOT overall}

Patients with at least one

of the ACSCOT criteria

$\begin{array}{rlll}5 & 3.3 & 3 & 2.0 \\ 0 & 0 & 0 & 0 \\ 4 & 2.6 & 1 & 0.7 \\ & & & \\ 0 & 0 & 0 & 0 \\ 0 & 0 & 0 & 0 \\ 7 & 4.6 & 0 & 0 \\ 0 & 0 & 0 & 0 \\ 2 & 1.3 & 0 & 0 \\ 18 & 11.9 & 4 & 2.6\end{array}$

$\begin{array}{llll}7 & 4.6 & 0 & 0\end{array}$

$\begin{array}{llll}22 & 14.6 & 7 & 4.6\end{array}$

$\begin{array}{llll}14 & 9.3 & 3 & 2.0\end{array}$

$\begin{array}{llll}11 & 7.3 & 8 & 5.3\end{array}$

$\begin{array}{llll}20 & 13.2 & 7 & 4.6\end{array}$

$\begin{array}{llll}74 & 49.0 & 25 & 16.6\end{array}$

ISS Injury Severity Score, GCS Glasgow Coma Scale, SBP systolic blood pressure, $R R$ respiratory rate, ACSCOT American College of Surgeons' Committee on Trauma 
Table 4 New prehospital items not included in the American College of Surgeons' Committee on Trauma triage guidelines

\begin{tabular}{|c|c|c|c|c|}
\hline & \multicolumn{2}{|c|}{$\begin{array}{l}\text { ISS }>15 \\
(N=151)\end{array}$} & \multicolumn{2}{|c|}{$\begin{array}{l}\text { ISS }=1-15 \\
(N=151)\end{array}$} \\
\hline & $N$ & $\%$ & $N$ & $\%$ \\
\hline \multicolumn{5}{|l|}{ Head } \\
\hline Pupil disorders & 62 & 41.1 & 10 & 6.6 \\
\hline Blood loss ear-nose-mouth & 45 & 29.8 & 11 & 7.3 \\
\hline Liquor loss ear-nose-mouth & 3 & 2.0 & 0 & 0 \\
\hline Vomiting & 22 & 14.6 & 5 & 3.3 \\
\hline Loss of consciousness & 96 & 66.7 & 19 & 13.0 \\
\hline \multicolumn{5}{|l|}{ Thorax } \\
\hline Compression pain & 24 & 15.9 & 7 & 4.6 \\
\hline Asymmetric trachea & 0 & 0 & 0 & 0 \\
\hline Rhonchi-crepitations & 3 & 2.0 & 1 & 0.7 \\
\hline Painful breathing & 15 & 9.9 & 7 & 4.6 \\
\hline Stridor & 2 & 1.3 & 0 & 0 \\
\hline Absent or decreased breath sounds & 2 & 1.3 & 16 & 10.6 \\
\hline \multicolumn{5}{|l|}{ Abdomen } \\
\hline $\begin{array}{l}\text { Compression pain and rebound } \\
\text { tenderness }\end{array}$ & 20 & 13.2 & 7 & 4.6 \\
\hline \multicolumn{5}{|l|}{ Extremities } \\
\hline Pain when moving limb & 34 & 22.5 & 94 & 62.3 \\
\hline Pain when compression axis & 17 & 11.3 & 64 & 42.4 \\
\hline Abnormal position limb & 24 & 15.9 & 57 & 37.7 \\
\hline \multicolumn{5}{|l|}{ Skin } \\
\hline Paleness & 54 & 35.8 & 21 & 13.9 \\
\hline Clamminess & 12 & 7.9 & 3 & 2.0 \\
\hline Edema & 1 & 0.7 & 1 & 0.7 \\
\hline \multicolumn{5}{|l|}{ Other } \\
\hline Heavy weight on patient $>50 \mathrm{~kg}$ & 2 & 1.3 & 0 & 0 \\
\hline $\mathrm{CO}$ intoxications & 2 & 1.3 & 0 & 0 \\
\hline
\end{tabular}

ISS Injury Severity Score, $C O$ carbon monoxide descriptions of injuries items with AIS 4 codes reflecting major trauma patients (ISS $>15$; i.e., minimal second-degree burns on $\geq 25 \%$ body surface or face, paralysis, depressed skull fracture, and amputation proximal to wrist or ankle). According to the new model, a patient should be directly transported to a trauma center when at least one of the nine items is met.

The newly developed model identified $92.1 \%$ of the major trauma patients with an ISS $>15$. Furthermore, this model had a specificity of $79.5 \%$, a PPV of $39.4 \%$, a NPV of $98.6 \%$, and an accuracy of $81.1 \%$. Compared to the ACSCOT model, the new model had a higher sensitivity $(p=0.023)$. Both models did not differ in terms of specificity $(p=0.711)$. Examining the new model for identifying patients with an ISS $\geq 18$ or an ISS $\geq 30$ resulted in a sensitivity of respectively $93.7 \%$ and $100 \%$ and a specificity of respectively $76.8 \%$ and $71.6 \%$. These findings did not significantly differ from the ACSCOT model $(p>0.05)$.

The new model did not identify 12 of the 151 major trauma patients with an ISS $>15$. These patients had a mean age of $47.2( \pm 26.4)$ years and a mean ISS of $20.9( \pm 4.6$; range 16-29). Almost two-third of these false negatives incurred extremity (66.7\%) injuries, whereas only $39.6 \%$ of the other major trauma patients, the true positives, sustained extremity injuries $(p=0.068)$. Furthermore, the false negatives mainly incurred head $(58.3 \%)$, thorax $(41.7 \%)$, and external injuries (33.3\%). Five of the misclassified patients had severe thorax injuries (AIS=4), three patients had severe head injuries (AIS $=4$ ) and one patient had a critical head injury (AIS $=5$ ). None of the vital parameters (GCS, SBP, and RR) were abnormal for these patients.

Table 5 New prehospital triage model with results from stepwise forward and stepwise backward logistic regression

\begin{tabular}{|c|c|c|c|c|c|c|c|c|}
\hline & & & \multirow[t]{2}{*}{$\beta$} & \multirow[t]{2}{*}{ SE } & \multirow[t]{2}{*}{ OR } & \multicolumn{2}{|c|}{$95 \% \mathrm{CI}$ for OR } & \multirow[t]{2}{*}{$p$} \\
\hline & & & & & & Lower & Upper & \\
\hline \multirow[t]{4}{*}{ Head } & 1 & GCS $<14$ & 2.262 & 0.450 & 9.600 & 3.971 & 23.208 & $<0.001$ \\
\hline & 2 & Loss of consciousness & 1.405 & 0.385 & 4.076 & 1.915 & 8.675 & $<0.001$ \\
\hline & 3 & Depressed skull fracture & & & & & & \\
\hline & 4 & Pupil disorders & 1.039 & 0.449 & 2.828 & 1.172 & 6.821 & 0.021 \\
\hline Thorax & 5 & Compression pain thorax & 1.818 & 0.512 & 6.158 & 2.256 & 16.811 & $<0.001$ \\
\hline Abdomen & 6 & Abdominal compression pain and rebound tenderness & 1.344 & 0.535 & 3.835 & 1.343 & 10.953 & 0.012 \\
\hline \multirow[t]{2}{*}{ Extremities } & 7 & Paralysis & & & & & & \\
\hline & 8 & Amputation proximal to wrist-ankle & & & & & & \\
\hline \multirow[t]{2}{*}{ Skin } & 9 & Burns $\geq 25 \%$ body surface or face & & & & & & \\
\hline & & Constant & -1.617 & 0.215 & 0.198 & & & $<0.001$ \\
\hline
\end{tabular}

Patients should be transported to a trauma center if at least one of nine items is met. Items 1, 2, 4, 5, and 6 are derived from logistic regression. Items 3, 7, 8, and 9 are ACSCOT anatomic items assigned with an Abbreviated Injury Scale of 4.

$S E$ Standard error, $O R$ odds ratio, $C I$ confidence interval, GCS Glasgow Coma Scale 


\section{Discussion}

To our knowledge, this is the first study to evaluate the validity of the US ACSCOT triage criteria in a European trauma system. Furthermore, other prehospital measurements, not included in the ACSCOT guidelines, were examined for triage use in the prehospital setting. Good prehospital triage criteria are important to ensure that the right patient is directly taken to the most appropriate hospital. Moreover, triage tools identifying severely injured patients are useful for trauma team activation at the Emergency Department.

The application of the ACSCOT guidelines in our dataset revealed a somewhat lower overall sensitivity (84\%) compared to previous studies reporting on the ACSCOT criteria in US datasets (sensitivity of 95-97\%) [15-17]. Only one study calculated the specificity of the ACSCOT criteria and reported a much lower specificity (8\%) than we found in our study (78\%) [17]. However, this study included patients with primarily motor vehicle crashes and falls transported by a helicopter [17]. Many patients in this study fulfilled one of the mechanistic ACSCOT criteria but were not severely injured resulting in a very low specificity. No study has yet reported on the specificity of the ACSCOT triage guidelines in a population-based dataset.

The percentages of major trauma patients in our study meeting the ACSCOT physiologic criteria $(63 \%)$ and the ACSCOT mechanism of injury descriptors (49\%) were highly comparable to previous studies reporting on sensitivity rates of $56-65 \%$ for the physiologic criteria and $45 \%$ for the mechanism of injury items [16-17]. However, the ACSCOT anatomic criteria resulted in a much lower sensitivity in our study (12\%) in contrast to a previously reported sensitivity of $45 \%$ [16]. This difference reflects differences in injury profiles between the US and European major trauma patients such as the low percentage of penetrating injuries in our dataset.

In this study, a new triage tool was developed including the following items: GCS $<14$, loss of consciousness, depressed skull fracture, pupil disorders, thorax compression pain, abdominal compression pain and rebound tenderness, paralysis, amputation proximal to wrist-ankle, and burns $\geq 25 \%$ body surface or face. This model identified significantly more major trauma patients with an ISS $>15$ than the ACSCOT model. The specificity was also better, though not statistically significant. Furthermore, for other ISS cutoff values, the performance of the new model was very much comparable to the ACSCOT.

In general, a sensitivity of $85 \%$ and an overtriage rate of $50 \%$ are accepted for prehospital triage criteria [20]. The newly developed model had a sensitivity of $92 \%$ and would have identified $58 \%$ more major trauma patients than the currently used triage tool (Revised Trauma Score $(\mathrm{RTS})<11$ ) [11]. The overtriage rate (one minus specificity) of the new model was $21 \%$. Trauma registry data showed us that in the study period a total of 3,192 minor trauma patients were transported in our trauma system to either the TCWN ( $n=$ $1,219)$ or to one of the regional hospitals $(n=1,973)$. Application of the new model to all 3,192 minor trauma patients would have resulted in 670 false positives (i.e., minor trauma patients wrongly identified as major trauma patients) directly transported to the TCWN. This comes down to 549 less patients than the 1,219 minor trauma patients who have actually been transported to the TCWN during the study period. Overall, the new model could have resulted in a decrease in the overtriage rate from $38 \%$ now to $21 \%$.

Unlike the ACSCOT guidelines, mechanistic factors were not included in the new model. Previous studies have also questioned the significance of the mechanistic criteria because these are prone to false positives [21-24]. For example, people involved in severe car crashes may be uninjured. Moreover, details of the mechanism of injury are not always clear due to lacking eyewitnesses or unconsciousness of the patient. Furthermore, the proposed model includes only one physiological item, i.e., the GCS. The GCS is a good predictor of brain injury [25]. The other physiological parameters, i.e., the systolic blood pressure and the respiratory rate, were excluded. This was not surprising as we found that three quarter of the patients with severe abdominal injuries had a blood pressure of $\geq 90$. Likewise, the majority of the patients with severe thorax injuries had normal respiratory rates. It is noteworthy that the GCS $<14$ would have identified even more major trauma patients than a RTS $<11$. Up to now, the RTS, containing the SBP, the RR, and the GCS, is one of the most commonly applied triage tools in the Netherlands. Our new model also includes the following ACSCOT anatomical items: a depressed skull fracture, paralysis, amputation proximal to wrist or ankle, and major burns. These injuries were scarce or even absent in our study population. We did include them in our model in view of the high severity of these injuries resulting in an ISS $>15$ most likely requiring trauma center treatment. These injuries are easy to recognize for the ambulance staff.

The debate about which patients need trauma center treatment should be continued to further define which patient should at least be identified by triage guidelines. In our study, we defined these patients as those with an ISS > 15. Furthermore, we also looked at the performance of the ACSCOT and the new model for patients with an ISS $\geq 18$ and an ISS $\geq 30$. Other studies have looked at resource use such as direct admission to an ICU or Emergency Surgery [26-28]. There is no golden standard, but recently it was proven that trauma patients with an $\mathrm{AIS} \geq 4$, i.e., patients with at least an ISS $>15$, benefit from trauma center treatment [4]. Moreover, we consider the ISS preferable to the resource use for defining major trauma patients in need of trauma center treatment. The AIS and the ISS are 
anatomically based, consensus-derived, unambiguous scores which are universally used and enhance comparisons.

This study has several shortcomings. First of all, we only included trauma patients treated in the level-one trauma center. A previous study indicated that the major trauma patients treated in non-trauma-center hospitals in our trauma system are less severely injured [11]. The degree to which the new triage model is able to correctly identify these patients needs to be investigated. Furthermore, children were excluded from the study population because children have other physiological and anatomic responses to trauma. Specific trauma scores, such as the pediatric trauma score have been developed for children [29]. We are conducting a study to evaluate the prehospital predictive value of these trauma scores for severely injured children. Finally, five mechanistic items of the ACSCOT triage guidelines could not be evaluated in this study as these criteria are not standardized items on the ambulance forms in the Netherlands.

The new model needs to be further developed and evaluated in a prospective study and in other European datasets. Probably all prehospital triage schemes in other countries that include the RTS will need to be adjusted in view of the small number of major trauma patients showing a lowered RTS in the prehospital setting [11].Trauma registries are indispensable for these kinds of evaluations. Likely, other regions or countries will adjust the triage model because of specific geographical differences, differences in available resources and expertise at the nontrauma-center hospitals, and differences in injury profiles. For instance, the major trauma patients in our study sustained less severe thorax and abdomen injuries compared to major trauma patients registered by the German Trauma registry [30]. Moreover, the triage decision in Germany is often not made by a paramedic but by an emergency physician at the scene which may lead to other criteria being included in the triage model.

Hopefully, in the future, a new triage model will assist ambulance staff to identify all major trauma patients who should be transported to trauma centers. Eventually, this may improve survival rates and even nonfatal outcomes.

Open Access This article is distributed under the terms of the Creative Commons Attribution Noncommercial License which permits any noncommercial use, distribution, and reproduction in any medium, provided the original author(s) and source are credited.

\section{References}

1. Sethi D, Racioppi F, Baumgarten I, Bertollini R (2006) Reducing inequalities from injuries in Europe. Lancet 368:2243-2250

2. Krug EG, Sharma GK, Lozano R (2006) The global burden of injuries. Am J Public Health 90:523-526
3. Holbrook TL, Anderson JP, Sieber WJ, Browner D, Hoyt DB (1999) Outcome after major trauma: 12-month and 18-month follow-up results from the Trauma Recovery Project. J Trauma 46:765-773

4. Nirula R, Brasel K (2006) Do trauma centers improve functional outcomes: a national trauma databank analysis? J Trauma 61:268271

5. Mackenzie EJ, Rivara FP, Jurkovich GJ, Nathens AB, Frey KP, Eglestone BL, Salkever DS, Scharfstein DO (2006) A national evaluation of the effect of trauma-center care on mortality. N Eng J Med 354:366-378

6. Sampalis JS, Denis R, Lavoie A, Frechette P, Boukas S, Nikolis A, Benoit D, Fleiszer D, Brown R, Shurchill-Smith M, Mulder D (1999) Trauma care regionalization: a process-outcome evaluation. J Trauma 46:565-579

7. Leppaniemi A (2005) Trauma systems in Europe. Curr Opin Crit Care 11:576-579

8. Probst C, Paffrath T, Krettek C, Pape HC, the German Trauma Registry (2006) Comparative update on documentation of trauma in seven national registries. Eur J Trauma 32:357-364

9. Haas NP (2002) The trauma center: now and in the future. J Bone Joint Surg Br 84:627-630

10. Batchelor JS (2000) Adult prehospital scoring systems: a critical review. Trauma 2:253-260

11. Sturms LM, Hoogeveen JM, le Cessie S, Schenk PE, Pahlplatz PVM, Hogervorst M, Jukema GN (2006) Prehospital triage and survival of major trauma patients in a Dutch regional trauma system: relevance of trauma registry. Langenbecks Arch Surg 391:343-349

12. Roorda J, van Beeck EF, Stapert JW, ten Wolde W (1996) Evaluating performance of the revised trauma score as a triage instrument in the prehospital setting. Injury 27:163-167

13. Gray A, Goyder EC, Goodacre SW, Johnson GS (1997) Trauma triage: a comparison of CRAMS and TRTS in a UK population. Injury 28:97-101

14. Mackersie RC (2006) History of trauma field triage development and the American College of Surgeons criteria. Prehosp Emerg Care 10:287-294

15. Lerner EB (2006) Studies evaluating current field triage: 19662005. Prehosp Emerg care 10:303-306

16. Norcross ED, Ford DW, Cooper ME, Zone-Smith L, Byrne TK, Yarbrough DR 3rd (1995) Application of American College of Surgeons' field triage guidelines by pre-hospital personnel. J Am Coll Surg 181:539-544

17. Wuerz R, Taylor J, Smith JS (1996) Accuracy of trauma triage in patients transported by helicopter. Air Med J 15:168-170

18. Baker SP, O'Neill B, Haddon W Jr, Long WB (1974) The Injury Severity Score: a method for describing patients with multiple injuries and evaluating emergency care. J Trauma 14:187-196

19. American Association for the Advancement of Automotive Medicine (AAAM) (1998) The abbreviated injury scale, 1990 revision (update 1998). AAAM, Barrington

20. Wolfe R, McKenzie DP, Black J, Simpson P, Gabbe BJ, Cameron PA (2006) Models developed by three techniques did not achieve acceptable prediction of binary trauma outcomes. J Clin Epidemiol 59:26-35

21. Lowe DK, Oh GR, Neely KW, Peterson CG (1986) Evaluation of injury mechanism as a criterion in trauma triage. Am J Surg 152:6-10

22. Velmahos GC, Jindal A, Chan LS, Murray JA, Vassiliu P, Berne TV, Asensio J, Demetriades D (2001) Insignificant mechanism of injury: not to be taken lightly. J Am Coll Surg 192:147-152

23. Hunt RC (1999) Is mechanism of injury dead? Prehosp Emerg care 3:70-73 
24. Cooper ME, Yarbrough DR, Zone-Smith L, Byrne TK, Norcross ED (1995) Application of field triage guidelines by pre-hospital personnel: is mechanism of injury a valid guideline for patient triage? Am Surg 61:363-367

25. Marmarou A, Lu J, Butcher I, McHugh GS, Murray GD, Steyerberg EW, Mushkudiani NA, Choi S, Maas AI (2007) Prognostic value of the Glasgow Coma Scale and pupil reactivity in traumatic brain injury assessed pre-hospital and on enrollment: an IMPACT analysis. J Neurotrauma 24:270-280

26. Gabbe BJ, Cameron PA, Wolfe R, Simpson P, Smith KL, McNeil JJ (2005) Prehospital prediction of intensive care unit stay and mortality in blunt trauma. J Trauma 59:458-465
27. Phillips JA, Buchman TG (1993) Optimizing prehospital triage criteria for trauma team alerts. J Trauma 34:127-132

28. Tamim H, Joseph L, Mulder D, Battista RN, Lavoie A, Sampalis JS (2002) Field triage of trauma patients: improving on the Prehospital Index. Am J Emerg Med 20:170-176

29. Tepas JJ 3rd, Mollitt DL, Talbert JL, Bryant M (1987) The pediatric trauma score as a predictor of injury severity in the injured child. J Pediatr Surg 22:14-18

30. Arbeitsgemeinschaft (AG) 'Polytrauma' der Deutschen Gesellschaft für Unfallchirurgie (DGU) (2003) Jahresbericht 2002 des Traumaregisters der AG 'Polytrauma'der DGU. AG Polytrauma DGU, Köln 